\title{
Does the saphenous nerve play an important role after major ankle surgery?
}

\section{BJØRN S1, WONG WY2, BAAS J1, NIELSEN KK1, BØRGLUM J3, HAURITZ RW4 and BENDTSEN TF1 \\ 1 Aarhus University Hospital, Denmark \\ 2 Tan Tock Seng Hospital, Singapore \\ 3 Zealand University Hospital, University of Copenhagen, Denmark \\ 4 Kolding Hospital, Denmark}

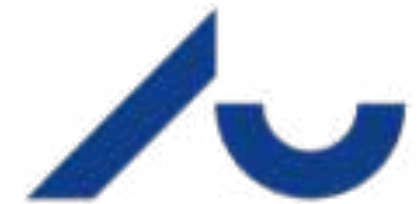

AARHUS UNIVERSITY

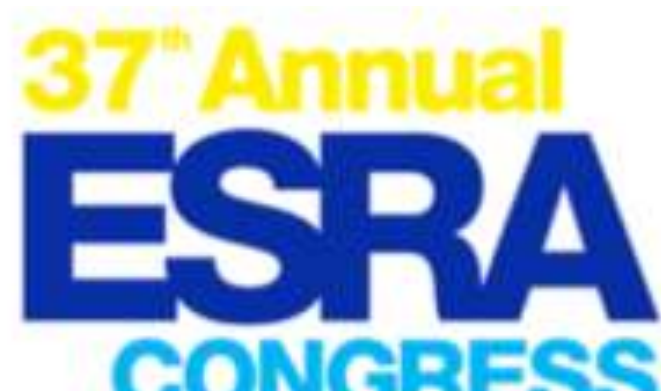

DUBLIN, IRELAND

12-15 SEPTEMBEA 2018
The importance of a sciatic nerve block after major ankle surgery is well-investigated, 1 whereas this study was the first randomized, controlled, double-blinded trial aimed to investigate the importance of a supplemental saphenous nerve block for patients undergoing major ankle surgery. ${ }^{2}$

We hypothesized that a saphenous nerve block reduces the proportion of patients experiencing significant clinical pain after major ankle surgery.

\section{Background and aims}
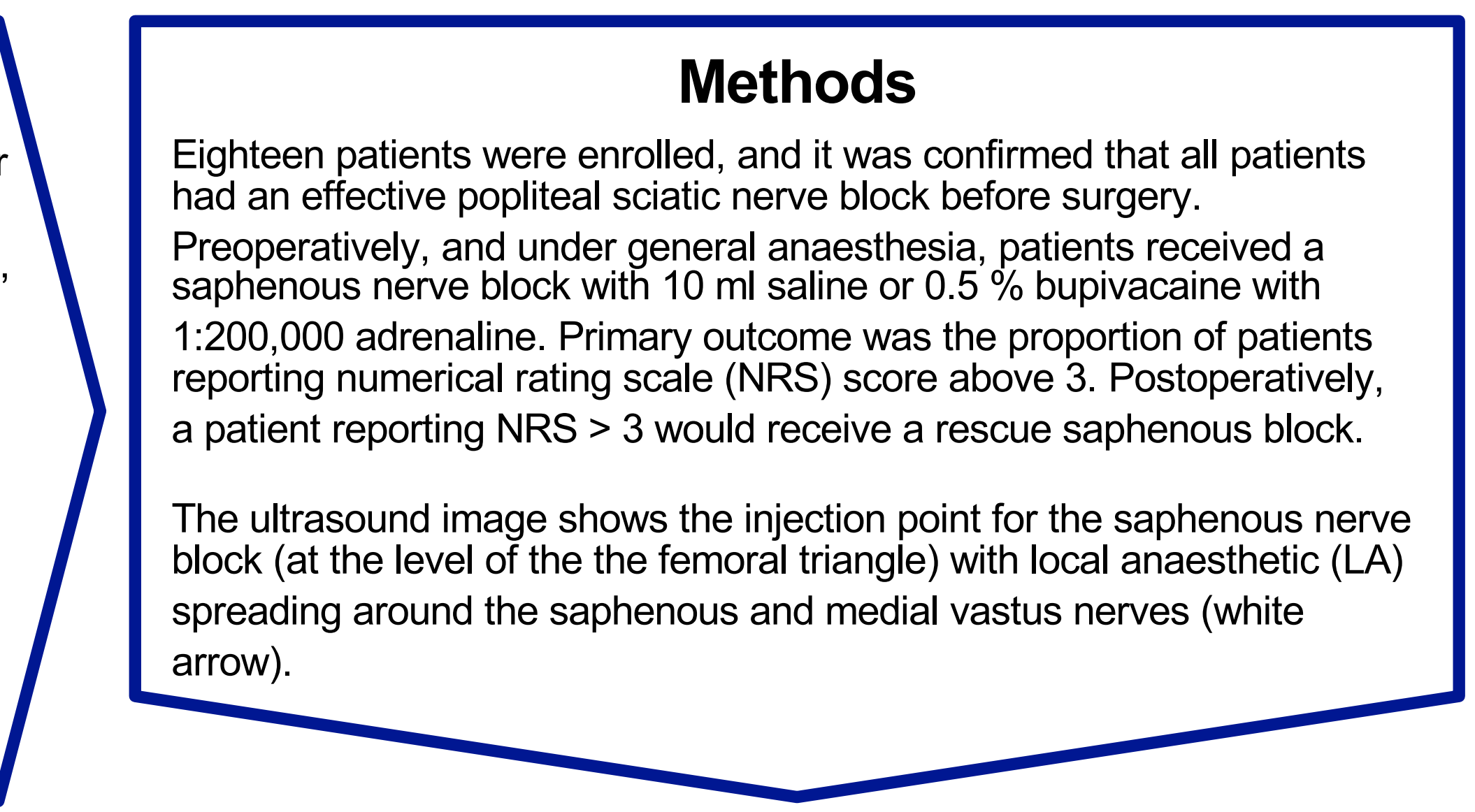

\section{Results}

The maximal pain scores (Fig. 1) were significantly lower in the active group (0 [0-0]) compared to the placebo group (5 [4-6]). In total 8 out of 9 patients in the placebo group reported NRS $>3$ within 30 minutes after PACU arrival versus 1 out of 9 patients in the active group $(P=0.003)$.

All patients with NRS $>3$ receiving a saphenous rescue block dropped to a pain score of 0 within 30 minutes.
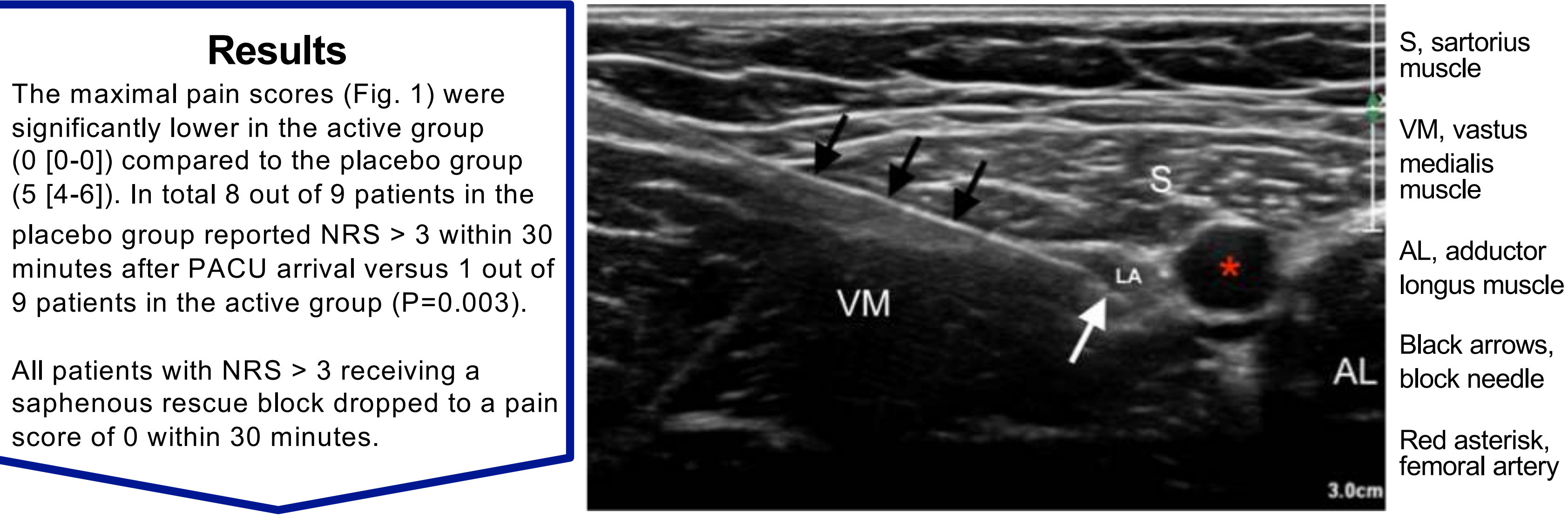

Fig. 1: Maximal pain score at the medial side of the ankle Significant pain developed within $\mathbf{3 0}$ minutes after PACU arrival

Number of patients

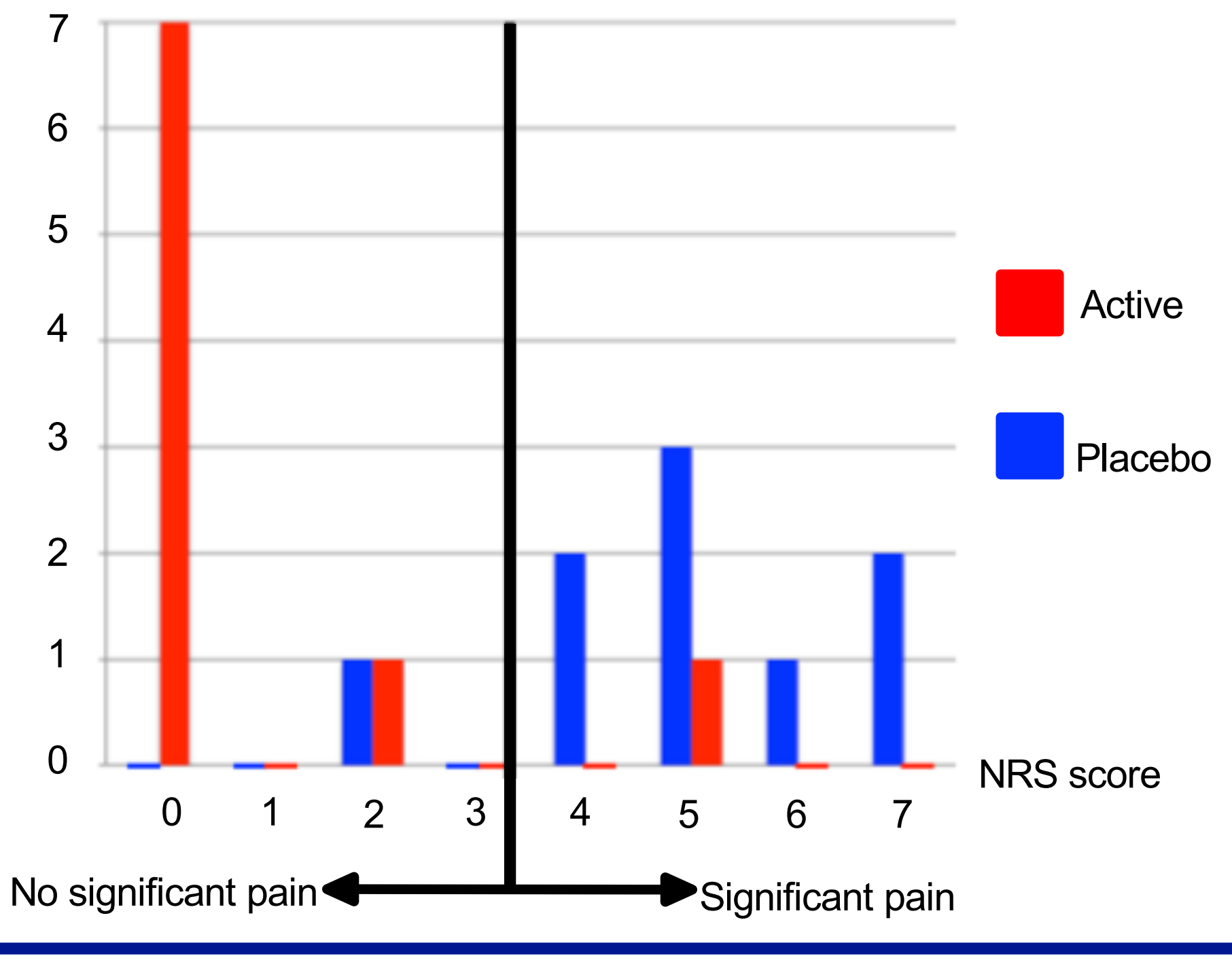

\section{Conclusion}

The saphenous nerve plays an important role after major ankle surgery, as the patients in the placebo group experienced moderate to severe pain from the medial side of the ankle, appearing within 30 minutes after PACU arrival.

All patients with NRS $>3$ receiving a rescue saphenous block became pain free, which underlines the importance of a saphenous nerve block as a supplement to a sciatic nerve block for patients undergoing major ankle surgery.

\section{References}

1. Chou LB et al. Postoperative pain following foot and ankle surgery: a prospective study. Foot Ankle Int. 2008;29: 1063-8.

2. Bjørn $S$ et al. The Importance of the Saphenous Nerve Block for Analgesia Following Major Ankle Surgery: A Randomized, Controlled, Double-Blind Study. Reg Anesth Pain Med. 2018; 43: 474-9 